Fixed Point Theory, 23(2022), No. 1, 391-426

DOI: $10.24193 /$ fpt-ro.2022.1.25

http://www.math.ubbcluj.ro/ nodeacj/sfptcj.html

\title{
GLOBAL AND LINEAR CONVERGENCE OF ALTERNATED INERTIAL SINGLE PROJECTION ALGORITHMS FOR PSEUDO-MONOTONE VARIATIONAL INEQUALITIES
}

\author{
BING TAN*, ADRIAN PETRUŞEL**, XIAOLONG QIN*** AND JEN-CHIH YAO*** \\ *Institute of Fundamental and Frontier Sciences, \\ University of Electronic Science and Technology of China, Chengdu, China \\ E-mail: bingtan72@gmail.com \\ ** Department of Mathematics, Babeş-Bolyai University, Cluj-Napoca, Romania \\ E-mail: petrusel@math.ubbcluj.ro \\ *** Department of Mathematics, Zhejiang Normal University, Zhejiang, China \\ E-mail: qxlxajh@163.com \\ (Corresponding author) \\ **** Department of Mathematics, Zhejiang Normal University, Zhejiang, China \\ E-mail: jen-chih.yao@zjnu.edu.cn
}

\begin{abstract}
In this paper, we investigate three new relaxed single projection methods with alternating inertial extrapolation steps and adaptive non-monotonic step sizes for solving pseudo-monotone variational inequalities in real Hilbert spaces. The proposed algorithms need to compute the projection on the feasible set only once in each iteration and they can work adaptively without the prior information of the Lipschitz constant of the mapping. The weak convergence theorems of the proposed iterative schemes are established under some appropriate conditions imposed on the parameters. These methods recover the Fejér monotonicity of the even subsequence with respect to the solution and obtain linear convergence rates. Finally, some numerical experiments and applications to optimal control problems are provided to demonstrate the advantages and efficiency of the proposed methods compared to some recent related ones.

Key Words and Phrases: Variational inequality, alternated inertial method, projection and contraction method, subgradient extragradient method, pseudo-monotone operator, adaptive stepsize. 2020 Mathematics Subject Classification: 47J20, 47J25, 47J30, 47H10, 68W10, 65K15.

\section{REFERENCES}

[1] F. Alvarez, H. Attouch, An inertial proximal method for maximal monotone operators via discretization of a nonlinear oscillator with damping, Set-Valued Anal., 9(2001), 3-11.

[2] E. Bonacker, A. Gibali, K.-H. Küfer, Nesterov perturbations and projection methods applied to IMRT, J. Nonlinear Var. Anal., 4(2020), 63-86.

[3] B. Bressan, B. Piccoli, Introduction to the Mathematical Theory of Control, AIMS Series on Applied Mathematics, San Francisco, 2007.

[4] L.C. Ceng, A subgradient-extragradient method for bilevel equilibrium problems with the constraints of variational inclusion systems and fixed point problems, Commun. Optim. Theory, 2021 (2021), Article ID 4.
\end{abstract}


[5] Y. Censor, A. Gibali, S. Reich, The subgradient extragradient method for solving variational inequalities in Hilbert space, J. Optim. Theory Appl., 148(2011), 318-335.

[6] Y. Censor, A. Gibali, S. Reich, Strong convergence of subgradient extragradient methods for the variational inequality problem in Hilbert space, Optim. Methods Softw., 26(2011), 827-845.

[7] Y. Censor, A. Gibali, S. Reich, Extensions of Korpelevich's extragradient method for the variational inequality problem in Euclidean space, Optimization, 61(2012), 1119-1132.

[8] S.Y. Cho, A convergence theorem for generalized mixed equilibrium problems and multivalued asymptotically nonexpansive mappings, J. Nonlinear Convex Anal., 21(2020), 1017-1026.

[9] S.Y. Cho, A monotone Bregan projection algorithm for fixed point and equilibrium problems in a reflexive Banach space, Filomat, 34(2020), 1487-1497.

[10] S.Y. Cho, Generalized mixed equilibrium and fixed point problems in a Banach space, J. Nonlinear Sci. Appl., 9(2016), 1083-1092.

[11] S.Y. Cho, Implicit extragradient-like method for fixed point problems and variational inclusion problems in a Banach space, Symmetry, 12(2020), 998.

[12] Q.L. Dong, Y.J. Cho, L.L. Zhong, T.M. Rassias, Inertial projection and contraction algorithms for variational inequalities, J. Global Optim., 70(2018), 687-704.

[13] Q.L. Dong, D. Jiang, A. Gibali, A modified subgradient extragradient method for solving the variational inequality problem, Numer. Algorithms, 79(2018), 927-940.

[14] Q.L. Dong, Y.Y. Lu, J. Yang, The extragradient algorithm with inertial effects for solving the variational inequality, Optimization, 65(2016), 2217-2226.

[15] A. Gibali, D.V. Thong, A new low-cost double projection method for solving variational inequalities, Optim. Eng., 21(2020), 1613-1634.

[16] A. Gibali, D.V. Thong, P.A. Tuan, Two simple projection-type methods for solving variational inequalities, Anal. Math. Phys., 9(2019), 2203-2225.

[17] B.S. He, A class of projection and contraction methods for monotone variational inequalities, Appl. Math. Optim., 35(1997), 69-76.

[18] D.V. Hieu, P.K. Anh, L.D. Muu, Modified hybrid projection methods for finding common solutions to variational inequality problems, Comput. Optim. Appl., 66(2017), 75-96.

[19] D.V. Hieu, J.J. Strodiot, L.D. Muu, An explicit extragradient algorithm for solving variational inequalities, J. Optim. Theory Appl., 185(2020), 476-503.

[20] F. Iutzeler, J.M. Hendrickx, A generic online acceleration scheme for optimization algorithms via relaxation and inertia, Optim. Methods Softw., 34(2019), 383-405.

[21] F. Iutzeler, J. Malick, On the proximal gradient algorithm with alternated inertia, J. Optim. Theory Appl., 176(2018), 688-710.

[22] O.S. Iyiola, Y. Shehu, Alternated inertial method for nonexpansive mappings with applications, J. Nonlinear Convex Anal., 21(2020), 1175-1189.

[23] G.M. Korpelevich, The extragradient method for finding saddle points and other problems, Èkonom. i Mat. Metody, 12(1976), 747-756.

[24] H. Liu, J. Yang, Weak convergence of iterative methods for solving quasimonotone variational inequalities, Comput. Optim. Appl., 77(2020), 491-508.

[25] X. Ma, H. Liu, An inertial Halpern-type CQ algorithm for solving split feasibility problems in Hilbert spaces, J. Appl. Math. Comput., (2021), DOI: 10.1007/s12190-021-01585-y.

[26] P.E. Maingé, M.L. Gobinddass, Convergence of one-step projected gradient methods for variational inequalities, J. Optim. Theory Appl., 171(2016), 146-168.

[27] Y. Malitsky, Projected reflected gradient methods for monotone variational inequalities, SIAM J. Optim., 25(2015), 502-520.

[28] Z. Mu, Y. Peng, A note on the inertial proximal point method, Stat. Optim. Inf. Comput., 3(2015), 241-248.

[29] F.U. Ogbuisi, Y. Shehu, J.C. Yao, An alternated inertial method for pseudomonotone variational inequalities in Hilbert spaces, Optim. Eng., (2021), DOI: 10.1007/s11081-021-09615-1.

[30] Z. Opial, Weak convergence of the sequence of successive approximations for nonexpansive mappings, Bull. Amer. Math. Soc., 73(1967), 591-597.

[31] M.O. Osilike, S.C. Aniagbosor, Weak and strong convergence theorems for fixed points of asymptotically nonexpansive mappings, Math. Comput. Model., 32(2000), 1181-1191. 
[32] B. Polyak, Some methods of speeding up the convergence of iteration methods, USSR Comput. Math. Math. Phys., 4(1964), 1-17.

[33] J. Preininger, P.T. Vuong, On the convergence of the gradient projection method for convex optimal control problems with bang-bang solutions, Comput. Optim. Appl., 70(2018), 221-238.

[34] Y. Shehu, Q.L. Dong, D. Jiang, Single projection method for pseudo-monotone variational inequality in Hilbert spaces, Optimization, 68(2019), 385-409.

[35] Y. Shehu, Q.L. Dong, L.L. Liu, Global and linear convergence of alternated inertial methods for split feasibility problems, Rev. Real Acad. Cienc. Exactas Fís. Nat. Ser. A Math. RACSAM, 115(2021), Article ID 53.

[36] Y. Shehu, A. Gibali, New inertial relaxed method for solving split feasibilities, Optim. Lett., 15(2021), 2109-2126.

[37] Y. Shehu, O.S. Iyiola, Strong convergence result for monotone variational inequalities, Numer. Algorithms, 76(2017), 259-282.

[38] Y. Shehu, O.S. Iyiola, Projection methods with alternating inertial steps for variational inequalities: Weak and linear convergence, Appl. Numer. Math., 157(2020), 315-337.

[39] Y. Shehu, X.H. Li, Q.L. Dong, An efficient projection-type method for monotone variational inequalities in Hilbert spaces, Numer. Algorithms, 84(2020), 365-388.

[40] Y. Shehu, L. Liu, X. Mu, Q.L. Dong, Analysis of versions of relaxed inertial projection and contraction method, Appl. Numer. Math., 165(2021), 1-21.

[41] B. Tan, J. Fan, S. Li, Self-adaptive inertial extragradient algorithms for solving variational inequality problems, Comput. Appl. Math., 40(2021), Article ID 19.

[42] B. Tan, L. Liu, X. Qin, Self adaptive inertial extragradient algorithms for solving bilevel pseudomonotone variational inequality problems, Jpn. J. Ind. Appl. Math., 38(2021), 519-543.

[43] P. Tseng, A modified forward-backward splitting method for maximal monotone mappings, SIAM J. Control Optim., 38(2000), 431-446.

[44] P.T. Vuong, Y. Shehu, Convergence of an extragradient-type method for variational inequality with applications to optimal control problems, Numer. Algorithms, 81(2019), 269-291.

Received: September 29, 2020; Accepted: April 24, 2021. 
